\title{
PV Smart Grid Monitoring System Based on Hybrid Telepot and Web Server
}

\author{
Eka Maulana $^{1}$, Ramadhani Kurniawan Subroto ${ }^{2}$, Lunde Ardhenta ${ }^{3}$ \\ 1,2,3 Departement of Electrical Engineering, Brawijaya University, Indonesia \\ ${ }^{1}$ Collaborative Research Center for Advanced System and Material Technology, Brawijaya University, Indonesia
}

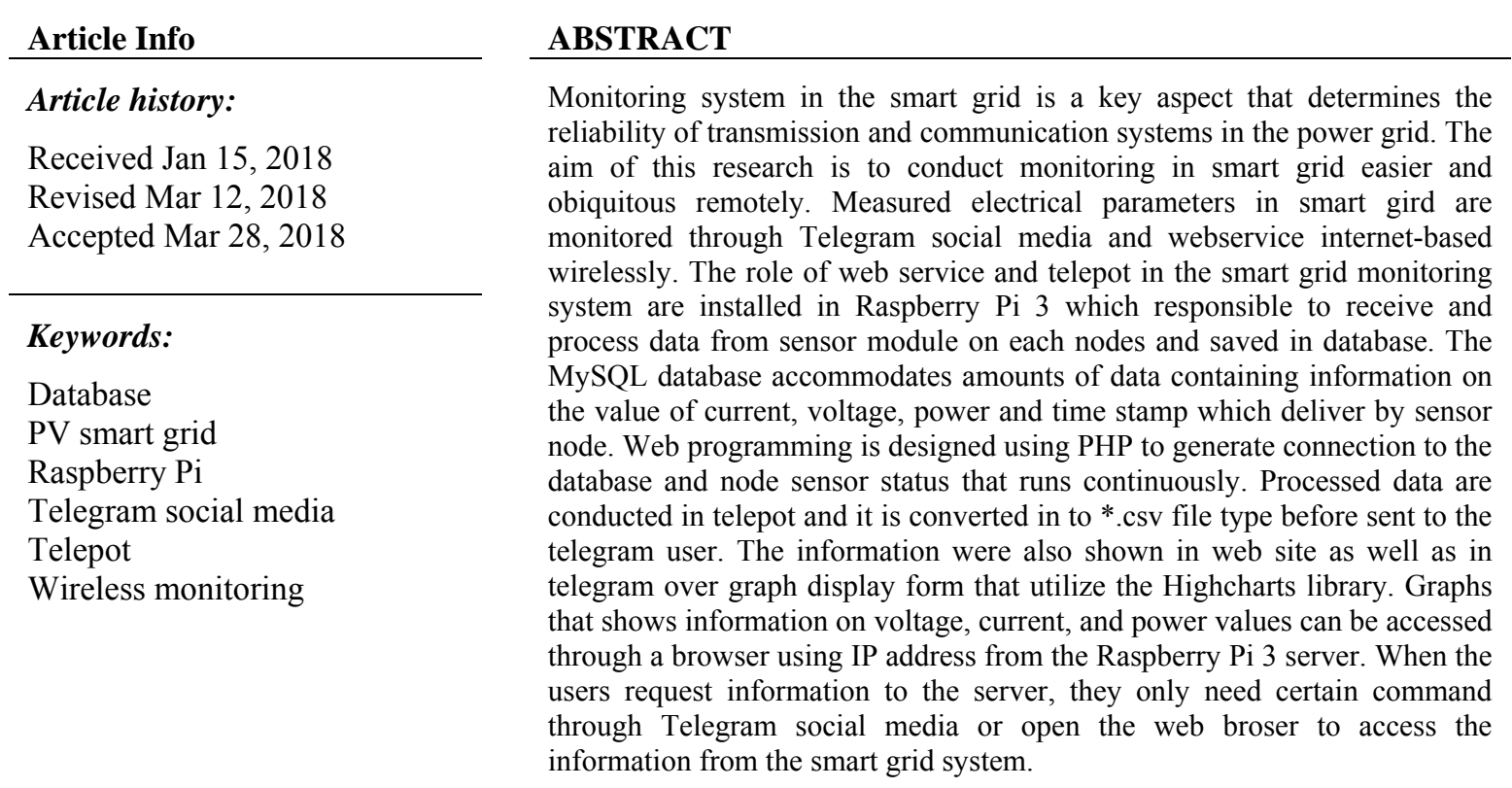

Copyright (C) 2018 Institute of Advanced Engineering and Science. All rights reserved.

\section{Corresponding Author:}

Eka Maulana,

Department of Electrical Engineering,

Brawijaya University,

Jalan Veteran No. 11, Malang, 65145, Indonesia.

Email: ekamaulana@ub.ac.id

\section{INTRODUCTION}

Utilization of renewable energy resources can be conducted using smart grid to provide renewable energy in Indonesia utilizing solar energy converted [1]-[5] into electrical energy to improve the efficiency of electricity use and build a micro-scale generator system. Indonesia has abundant renewable energy, but its utilization is relative small. In addition solar cells implementation, to build micro-scale systems can also combine wind turbines. The solar cell module is combined with a wind turbine generator and each section or node consists of generator, storage, control, and load elements supported by converter or inverter [6]. Interconnected nodes are connected to build DC power buses and equipped with communication lines to transmit monitored data directly or using smart control devices applied [7]-[8]. The use of electric energy continues to increase every year. This is due to inefficient use of electrical energy, especially in the household sector. This is shown in the data of sales of the largest electricity energy in Indonesia in 2014 occurred in the household sector which amounted to $42.34 \%$ of the total electricity sales. The growing demand for electrical energy is not proportional to the availability of electrical energy in Indonesia. Therefore, it takes a solution by utilizing renewable energy using hybrid experimental approximation [9]. 
Smart grid is a computerized and automated power grid. In the smart grid, it allows two-way communication between users and energy providers. In addition, transfer of electrical energy that occurs not only from the manufacturer to the user, but also vice versa [10]. Smart grid is one solution that uses renewable electrical energy. The use of smart grid as a renewable energy source needs a way to monitor the smart grid of each node to find out whether the smart grid is installed properly or not. Real time monitoring and display of power system components and performance, along the connection and in large geographic areas, helps operators to understand and optimize the behavior and performance of smart grid system components [11]-[16]. Smart grid monitoring process can be accessed wirelessly by using internet, so electrical parameters value can be monitored remotely through social media. This system is designed using smart grid monitoring system internet-based and application of the IoT for the smart grid system[17]-[19].

The aim of this paper is to provide a technical overview of realizable techniques for monitoring and control of smart grids based on real time information, actions and monitoring for efficient, applied design and information access easier. These techniques are analyzed in detail and their effectiveness has been demonstrated with internet based via web service and telepot bot api. This system requires a server that role to receive and process data sensors installed on each node, so the data can be sent to the user through social media especially Telegram and through a web page. Smart grid monitoring via Telegram social media and the web employ a server run by Raspberry Pi 3 to make cheaper one. The data from the sensor module will be stored in the MySQL database through the PHP program and will be presented in graphical form through a website page. Meanwhile, the server in charge of receiving command from user and sending file (*.csv) via Telegram will be run by Python program. The file sent will contain all the information stored in the database. It is expected that this study will provide an improvement in the problems found in the design of smart grid monitoring systems that can be done remotely through Telegram's social media and websites.

\section{RESEARCH METHOD}

\subsection{System Block Diagram}

The wireless smart grid monitoring system active when the sensor module on each smart grid node receive the data of voltage and current values in which the data will be sent to the server via internet. The internet connection is used as a transfer media for smart grid monitoring data. By using the internet, monitoring process can be done remotely. in other hand, the server acts as a center to process data received from each sensor module on the smart grid. Processed data will be displayed on the website and can be accessed through social media telegram. Users can perform smart grid monitoring through social media Telegram by sending certain commands so the data received in accordance with the orders sent message. In general, the overall system design block diagram is shown in Figure 1.

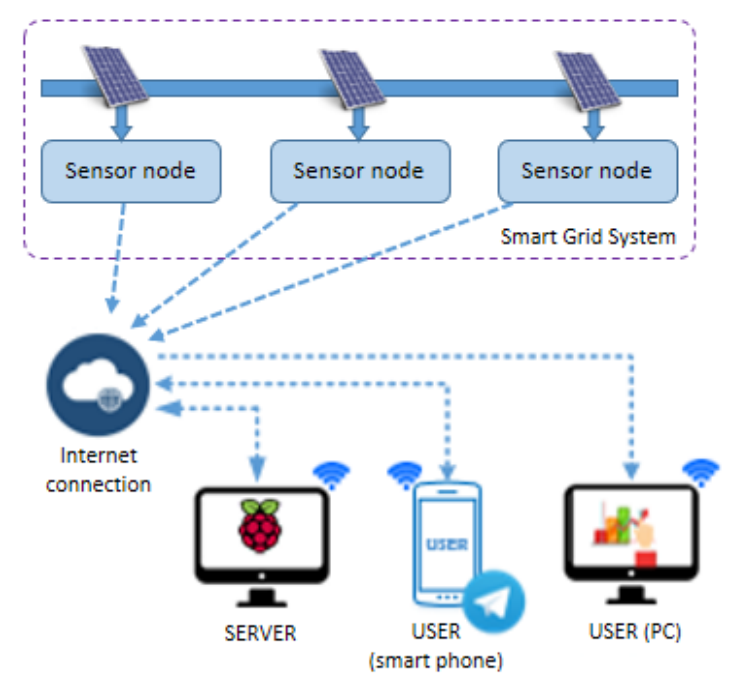

Figure 1. Block Diagram of Smart Grid Monitoring System

\subsection{System Specification}

Device specification consist of Raspberry Pi 3 which used as a server that receives and processes data readings of sensors. Monitoring system using social media Telegram and website are combined to access 
the information. The process of sending data to social media Telegram is done by sending certain commands to the Python server. The bandwidth used is $15 \mathrm{Mbps}$ of internet connection and the system send to the user (smartphone) in *.csv format by request automaticaly.

\subsection{Software Design}

The design of the software is used to control and manage the work of the tool as a whole. Server is designed by Phyton and Bot Api Telegram. Phyton software design works to run programs that are able to read the database, receive the command from the user, create a* .csv file, and send it to the user. The design of PHP software is used to receive data from the smart grid sensor module and put it into the MySQL database. In addition, the PHP program is used to create graphical views of data stored in the MySQL database. Data delivery process of each block is done wirelessly. The proposed smart grid monitoring system is used 3 sensor nodes and the data transmit wirelessly. Each node will transmit data of measured voltage, current, and power in the tables in the database that have been created. Smart grid monitoring is done through social media Telegram through Python program. Python will send files that can be opened with android applications such as Excel or WPS Office. Block diagram of transmitting data to MySQL database shown in Figure 2.

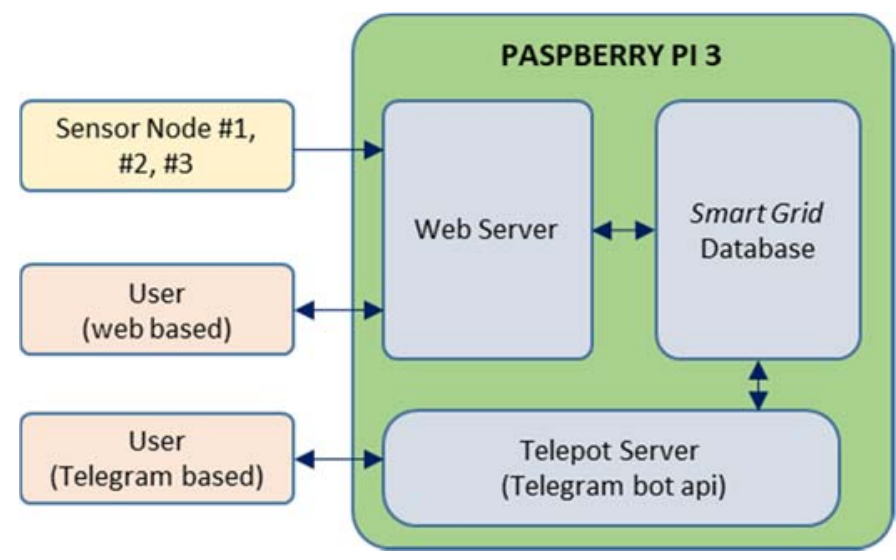

Figure 2. Block Diagram of data transmission from sensor nodes and users to the database

The database is created to hold all data of sensor readings on each node- 1 , node- 2 , node- 3 . The database for each node is constructed with a 5 column structure that will contain the information id, voltage, current, power, and time as shown in Table 1.

Table 1. Smart grid database table structure

\begin{tabular}{cccc}
\hline Column name & Data Type & Extra & Primary Key \\
\hline ID & Integer & Auto_Increment & $\sqrt{ }$ \\
Voltage & Decimal $(5,2)$ & - & - \\
Current & Decimal $(5,2)$ & - & - \\
Power & Decimal $(5,2)$ & - & - \\
Time & Datetime & - & - \\
\hline
\end{tabular}

\section{RESULTS AND ANALYSIS}

\subsection{Sensor Data Transmitting}

The purpose of testing is to know the data received MySQL database is the same as that sent by the sensor module installed on the smart grid node. Transmitted data were constructed through PHP programming is shown in Table 2 . The data delivery is sent by node- 1 to the server directly. In this test, a packed of data was sent to the database that has been provided through the web by determining local IP address in Rapberry Pi 3. 
Table 2. Data transmission sensor node 1 to the database

\begin{tabular}{ccc}
\multicolumn{3}{c}{ Data in Database } \\
$\mathrm{V}$ & $\mathrm{I}$ & $\mathrm{P}$ \\
\hline 0,3 & 0,42 & 0,12 \\
1,7 & 0,4 & 0,68 \\
3,29 & 0,42 & 1,37 \\
4,9 & 0,43 & 2,11 \\
6,3 & 0,5 & 3,13 \\
7,95 & 0,62 & 4,89 \\
9,41 & 0,74 & 7 \\
10,99 & 0,89 & 9,82 \\
12,51 & 1,05 & 13,17 \\
\hline
\end{tabular}

\subsection{Database Test}

The purpose of testing is to determine the duration of data transmission from the smart grid sensor module to the MySQL database. Testing the speed of delivery is done by providing a delay (delay time) that varies on the sensor module to send data to the MySQL database. Delay given is 5 seconds, 8 seconds, 10 seconds, and 15 seconds. Obtained a stable delay is 10 seconds. Table 3 shows the most stable delay is 10 seconds with an average of 10.3 seconds.

Tabel 3 Kecepatan pengiriman data ke database

\begin{tabular}{|c|c|c|c|}
\hline $\begin{array}{l}\text { Delay } \\
\text { (ms) }\end{array}$ & Time (H:M:S) & $\begin{array}{c}\text { Delay at Database } \\
\text { (s) }\end{array}$ & $\begin{array}{l}\text { average } \\
\text { Delay (s) }\end{array}$ \\
\hline \multirow{10}{*}{5000} & $15: 59: 23$ & - & \multirow{10}{*}{10.5} \\
\hline & $15: 59: 29$ & 6 & \\
\hline & $15: 59: 35$ & 6 & \\
\hline & $15: 59: 56$ & 21 & \\
\hline & $16: 00: 19$ & 23 & \\
\hline & $16: 00: 25$ & 6 & \\
\hline & $16: 00: 39$ & 14 & \\
\hline & $16: 00: 46$ & 7 & \\
\hline & $16: 00: 52$ & 6 & \\
\hline & $16: 00: 58$ & 6 & \\
\hline \multirow{10}{*}{8000} & $16: 30: 06$ & - & \multirow{10}{*}{9.5} \\
\hline & $16: 30: 16$ & 10 & \\
\hline & $16: 30: 25$ & 9 & \\
\hline & $16: 30: 35$ & 10 & \\
\hline & $16: 30: 45$ & 10 & \\
\hline & $16: 30: 54$ & 9 & \\
\hline & $16: 31: 04$ & 10 & \\
\hline & $16: 31: 13$ & 9 & \\
\hline & $16: 31: 23$ & 10 & \\
\hline & $16: 31: 32$ & 9 & \\
\hline \multirow{10}{*}{10000} & $16: 05: 57$ & - & \multirow{10}{*}{10.3} \\
\hline & $16: 06: 09$ & 12 & \\
\hline & $16: 06: 20$ & 11 & \\
\hline & $16: 06: 31$ & 11 & \\
\hline & $16: 06: 43$ & 12 & \\
\hline & $16: 06: 54$ & 11 & \\
\hline & $16: 07: 05$ & 11 & \\
\hline & $16: 07: 17$ & 12 & \\
\hline & $16: 07: 28$ & 11 & \\
\hline & $16: 07: 40$ & 12 & \\
\hline \multirow{10}{*}{15000} & $16: 12: 53$ & - & \multirow{10}{*}{16.4} \\
\hline & $16: 13: 10$ & 17 & \\
\hline & $16: 13: 26$ & 16 & \\
\hline & $16: 13: 42$ & 16 & \\
\hline & $16: 13: 59$ & 17 & \\
\hline & $16: 14: 15$ & 16 & \\
\hline & $16: 14: 31$ & 16 & \\
\hline & $16: 14: 48$ & 17 & \\
\hline & $16: 15: 04$ & 16 & \\
\hline & $16: 15: 21$ & 17 & \\
\hline
\end{tabular}




\subsection{Graph Display}

The purpose of this test is to determine whether the data presented on the graph in accordance with the data stored on the database. The test displays the graph shown in Figure 3. Based on Figure 3, we get the values of voltage, current, and power respectively of $2.24 \mathrm{~V}, 0.25 \mathrm{~A}$, and $0.56 \mathrm{~W}$. The values appear on the graph correspond to the values contained in the MySQL database. But the time shown is different from the time stored in the database.

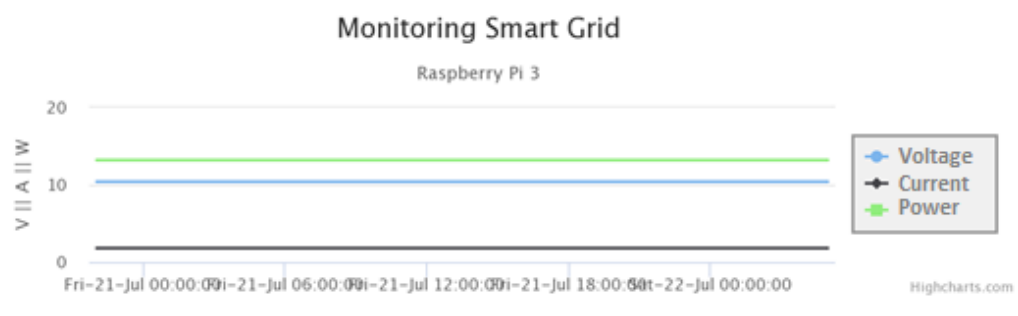

(a)

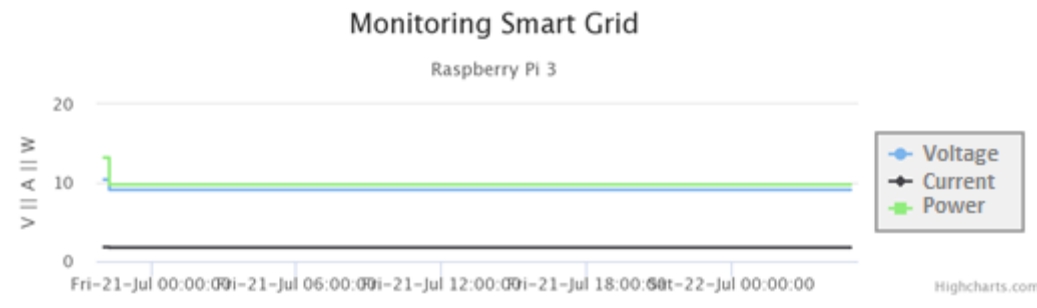

(b)



(c)

Figure 3. Monitoring graph of smart grid on website (a) node \#1 (b). node \#2 (c). node \#3.

\subsection{Command Testing}

Testing the delivery of commands from social media Telegram is to determine whether the messages sent users through social media Telegram can be accepted by Python program. Testing is conducted by typing messages through social media Telegram and sending to the server run by Python program.

Table 4. Testing Result of Sent Command

\begin{tabular}{ccc}
\hline Sent message & Received message & Respon Server Python \\
\hline /start & /start & - \\
Tes & Tes & Test \\
Roll & Roll & Random value 1-100 \\
Time & Time & Current time \\
Test & Test & - \\
Bot Telegram & Bot Telegram & - \\
Monitoring & Monitoring & - \\
Smart Grid & Smart Grid & - \\
Raspberry Pi 3 & Raspberry Pi 3 & - \\
\hline
\end{tabular}


Based on Table 4, it can be concluded that the process of sending messages from social media Telegram can run well. All messages can be received in accordance with the sent by the user is shown in Figure 4.



Figure 4. Phython Shell Program Window

Messages sent by the user will get a response from the server if the message is defined in the Python program. If the message sent is not in the program definision then the server will not respond or reply.

\subsection{Testing of Data}

This test aims to determine whether the file (*.csv) can be sent by the server to the user or not. This test is performed with the user sending messages with a specific format that contains date and time information. So the Python program will execute the function to read the data in the database in accordance with the desired time range. The data transmission tests are shown in Figure 5.
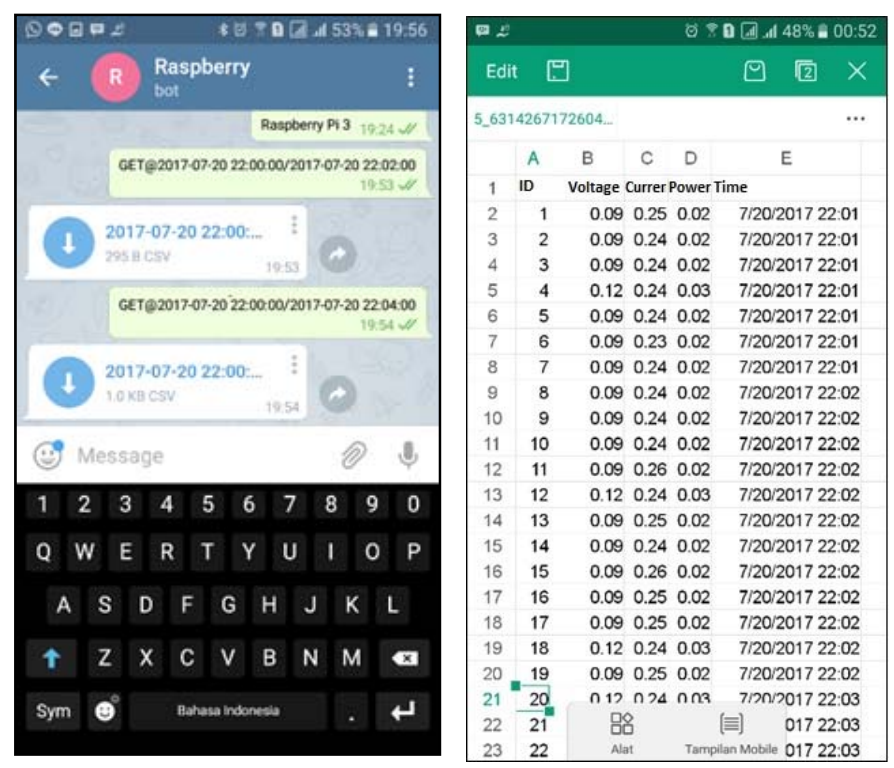

Figure 5. Telegram Message and File Delivery *.csv to User on Telegram

Database test aims to determine the capacity (size) of data stored in the database. Testing is observed by filling the database of 100 to 1000 lines containing the information values of voltage, current, power and time when the data is stored in the database. The memory zise testing in shown in Table 5. 
Table 5. Memory size on database

\begin{tabular}{cc}
\hline Row (Database) & Memory \\
\hline 100 & $16 \mathrm{~KB}$ \\
200 & $16 \mathrm{~KB}$ \\
300 & $16 \mathrm{~KB}$ \\
400 & $48 \mathrm{~KB}$ \\
500 & $48 \mathrm{~KB}$ \\
600 & $64 \mathrm{~KB}$ \\
700 & $64 \mathrm{~KB}$ \\
800 & $64 \mathrm{~KB}$ \\
900 & $64 \mathrm{~KB}$ \\
1000 & $64 \mathrm{~KB}$ \\
\hline
\end{tabular}

The overall test is performed to determine the performance of the system that has been designed. Tests conducted include:

1. Deliver messages from the user to the server to send * .csv files. The result of sending message and files are shown if Table 6.

Table 6. Testing the sending of commands and files

\begin{tabular}{ccccc}
\hline Test No & \multicolumn{2}{c}{ Telegram Messages } & \multicolumn{2}{c}{ File delivery } \\
& Sent & Not Sent & Sent & Not Sent \\
\hline 1 & $\sqrt{ }$ & - & $\sqrt{ }$ & - \\
2 & $\sqrt{ }$ & - & $\sqrt{ }$ & - \\
3 & $\sqrt{ }$ & - & $\sqrt{ }$ & - \\
4 & $\sqrt{ }$ & - & $\sqrt{ }$ & - \\
5 & $\sqrt{ }$ & - & $\sqrt{ }$ & - \\
6 & $\sqrt{ }$ & - & $\sqrt{ }$ & - \\
7 & $\sqrt{ }$ & - & $\sqrt{ }$ & - \\
8 & $\sqrt{ }$ & - & $\sqrt{ }$ & - \\
9 & $\sqrt{ }$ & - & $\sqrt{ }$ & - \\
10 & $\sqrt{ }$ & - & $\sqrt{ }$ & - \\
\hline Error & \multicolumn{5}{c}{$0 \%$} &
\end{tabular}

2. Testing file size *..csv and long delivery time. The result of testing file zise and delivery time are shown in Table 7.

Table 7. File size *.csv and long delivery time

\begin{tabular}{ccc}
\hline Row & Memory & Time (s) \\
\hline 100 & $3,8 \mathrm{~KB}$ & 5.18 \\
200 & $7,7 \mathrm{~KB}$ & 7.24 \\
300 & $11,7 \mathrm{~KB}$ & 9.69 \\
400 & $15.6 \mathrm{~KB}$ & 11.36 \\
500 & $19,5 \mathrm{~KB}$ & 14.79 \\
600 & $23,4 \mathrm{~KB}$ & 17.01 \\
700 & $27,3 \mathrm{~KB}$ & 20.29 \\
800 & $31,2 \mathrm{~KB}$ & 23.69 \\
900 & $35,1 \mathrm{~KB}$ & 25.64 \\
1000 & $39.0 \mathrm{~KB}$ & 30.12 \\
\hline
\end{tabular}

According to the Table 6, it is obtained the test results sending *.csv file to the user that the largest file size that is $39.0 \mathrm{~KB}$ with 30.12 seconds of delivery time. The transmitted file contains 1000 lines of smart grid sensor reading module data. As for the file containing 100 rows of data has a size of $3.8 \mathrm{~KB}$ and the required delivery time is 5.18 seconds. This is proportional to the amount of data read by the server and stored in the file. The result of sending * .csv file to user can be opened with android application such as MS Excel or WPS Office. 


\section{CONCLUSION}

According to the design on PV smart grid monitoring system, all of the parts have been successfully implementated and characterized. The designed PHP program successfully receives data from the sensor module and stores it into the table of each node in the MySQL database. The time required by the sensor module to send data to the database wirelessly requires a 10 second with an average time of 10.3 seconds. MySQL database reading through Python program works well. The database read has 3 tables which each has 5 columns. Smart grid monitoring graphs successfully display data in accordance with the data stored in the database. The message delivery and file delivery *.csv are working with $100 \%$ success rate.

\section{ACKNOWLEDGEMENTS}

This work is supported by LPPM Universitas Brawijaya and Collaborative Research Center for Andvanced System and Material Technology, Brawijaya University.

\section{REFERENCES}

[1] E. Maulana, S.H. Pramono, D. Fanditya, M. Julius, "Effect of Chlorophyll Concentration Variations from Extract of Papaya Leaves on Dye-Sensitized Solar Cell". World Academy of Science, Engineering and Technology, International Journal of Electrical, Computer, Energetic, Electronic and Communication Engineering, vol. 9(1), pp. 49-52, 2015.

[2] Muslichin, A. Mu'minin, A.H.Y. Fridasavema, M.A.R. Sembiring, C.M. Septani, E. Maulana, "The Thickness and Firing Duration Dependence of Titanium Dioxide (TiO2) Nanoparticle Against to the Output Power of Dyesensitized Solar Cell (DSSC)”. International Journal of Applied Engineering Research, vol. 10(18), pp. 38774$38777,2015$.

[3] S.H. Pramono, E. Maulana, "Organic Solar Cell based on extraction of Papaya (Carica papaya) and jatropha (Ricinus communis) leaves in DSSC (Dye Sensitized Solar Cell)". International Conf. on Edu. Tech and Science 2013 (pp. 248-251), 2013.

[4] S.H. Pramono, et al., "The effect of photoelectrode TiO2 layer thickness to the output power of chlorophyll-based Dye-Sensitized Solar Cell (DSSC). Intelligent Technology and Its Applications (ISITIA), International Seminar on, pp. 107-112. IEEE. 2015.

[5] S.H. Pramono, E. Maulana, A.F. Prayogo, R. Djatmika, "Characterization of Dye-Sensitized Solar Cell (DSSC) based on Chlorophyll Dye", International Journal of Applied Engineering Research, vol. 10(1), pp. 193-205, 2015.

[6] M. Satyanarayana, P. Satish Kumar. "Analysis and Design of Solar Photo Voltaic Grid Connected Inverter". Indonesian Journal of Electrical Engineering and Informatics (IJEEI), Vol. 3, No. 4, pp. 199-208, December 2015.

[7] S.H. Pramono, E. Maulana, H. Suyono, A. Zainuri, "Analytical Design of Low Voltage DC Micro-Grid System". ARPN Journal of Enginerring and Applied Science. Vol. 11, No. 5, pp. 2841-2848. 2016.

[8] J.O. Petinrin, M. Shaaban, "Overcoming Challenges of Renewable Energy on Future Smart Grid", TELKOMNIKA, Vol.10, No.2, June 2012, pp. 229-234

[9] M.N. Lakhoua, N. Walid, C. Atef, "System Analysis of a Hybrid Renewable Energy System", International Journal of Electrical and Computer Engineering (IJECE), Vol. 4, No. 3, pp. 343-350, June 2014.

[10] C.He-Rui, P. Xu, "Study on Smart Grid System Based on System Dynamics", TELKOMNIKA Indonesian Journal of Electrical Engineering Vol. 12, No. 12, pp. 7979-7986, December 2014.

[11] R.K. Subroto, L. Ardhenta, and E. Maulana, "A Novel of Adaptive Sliding Mode Controller with Observer for DC/DC Boost Converters in Photovoltaic System", The 5th International Conference on Electrical, Electronics, and Information Engineering, pp. 1-7, 2017.

[12] R.K. Subroto and K.L. Lian, "Modeling of a Multilevel Voltage Source Converter using the Fast Time-Domain Method", IEEE Journal of Emerging and Selected Topics in Power Electronics, vol. 2, no. 4, pp. 1117-1126, Dec. 2014.

[13] E. Maulana, L. Ardhenta, R.K Subroto, P. Mudjiraharjo, H. Suyono, "Wireless Smart Grid Monitoring System Based on Internet of Things (IoT) via Telegram and Website", Renewable Energy and Green Technology International Conference (REEGETECH 2017), pp.1-5, 2017.

[14] S.H. Pramono, S.N. Sari, E. Maulana, "Internet-Based Monitoring and Protection on PV Smart Grid System". Sustainable Information and Engineering Technology (SIET 2017) International Conference. pp. 1-6, 2017.

[15] S. Jaloudi, E. Ortjohann, A. Schmelter, P. Wirasanti, D. Morton.Communication strategy for grid control and monitoring of distributed generators in Smart Grids using IEC and IEEE standards. 2011 2nd IEEE PES International Conference and Exhibition on Innovative Smart Grid Technologies, pp. 1-6, 2011.

[16] N. Saputro, K. Akkaya, "Investigation of Smart Meter Data Reporting Strategies for Optimized Performance in Smart Grid AMI Networks". IEEE Internet of Things Journal, vol. 4(4), pp. 894-904, 2017.

[17] J.E.S. de Haan, P.H. Nguyen, W.L. Kling, P.F. Ribeiro, "Social interaction interface for performance analysis of smart grids", IEEE First International Workshop on Smart Grid Modeling and Simulation (SGMS), pp. 79-83, 2011.

[18] R.V. Jadhav, S.S. Lokhande, V.N. Gohokar, "Energy Management System in Smart Grid using Internet of Things", 2016 IEEE 1st International Conference on Power Electronics, Intelligent Control and Energy Systems (ICPEICES), pp. 1-4, 2016. 
[19] S. Ciavarella, J.Y. Joo, S. Silvestri, "Managing Contingencies in Smart Grids via the Internet of Things", IEEE Transactions on Smart Grid, vol. 7(4), pp. 2134-2141, 2016.

\section{BIOGRAPHIES OF AUTHORS}
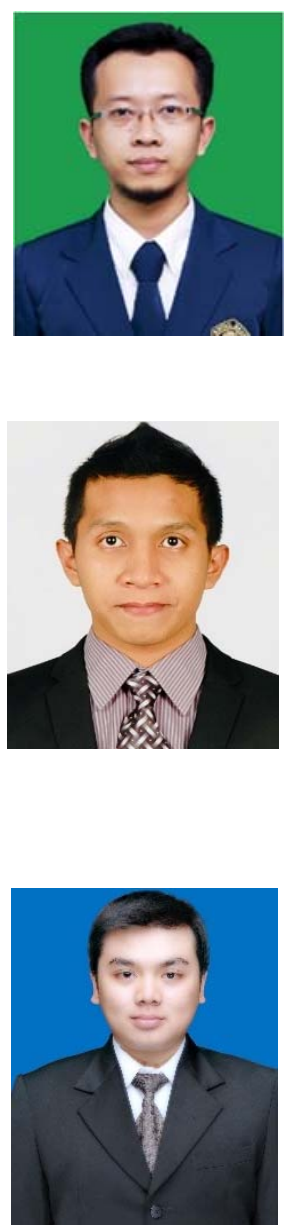

Eka Maulana received the B.Eng. (2009), M.Eng. (2011), degrees in Electrical Engineering from Brawijaya University (Indonesia) and University of Miyazaki (Japan), respectively. Currently he is a Lecturer and researcher in Department of Electrical Engineering, Brawijaya University. His researches are in fields of electronics, power electronics, smart grids, renewable energy and energy harversting devices, molecular electronics, sensors and photonic applications. His affiliations are member of IEEE, PSeeM-RG (Power System Engineering and Energy Management Research Group) and CRC-ASMAT (Collaborative Research Center for Advanced System and Material Technology) Brawijaya University. Further info on his homepage: http://maulana.lecture.ub.ac.id

Ramadhani Kurniawan Subroto received B.Eng. degree in electrical engineering from Institut Teknologi Sepuluh Nopember in 2012 and the M.Eng. and M.Sc. degrees from Institut Teknologi Sepuluh Nopember and the National Taiwan University of Science and Technology, Taiwan in 2014. He is currently a Lecturer in Electrical Engineering Department with the Brawijaya University, Malang, Indonesia. His main interest research includes harmonics analysis, harmonics modeling of power converters, control of power electronics, nonlinear control, sliding mode control, and observer design.

Lunde Ardhenta received the M.S. degree in Department of Electrical Engineering, National ChiaYi University, Taiwan in 2015. He completed his Bachelor degree in Department of Electrical Engineering, University of Brawijaya, Indonesia in 2011. He is a Lecturer in Department of Electrical Engineering, Brawijaya University. His research interests include renewable energy applications, digitalized control techniques for power electronics apparatus and systems, and optimal control theory. 